Check for updates

Cite this: Chem. Commun., 2018, 54, 13391

Received 6th September 2018, Accepted 5th November 2018

DOI: $10.1039 / c 8 c c 07227 b$

rsc.li/chemcomm

\section{A supramolecular porous material comprising Fe(II) mesocates†}

\author{
Benjamin H. Wilson, ${ }^{a}$ Hayley S. Scott, ${ }^{a}$ Omid T. Qazvini, ${ }^{b}$ Shane G. Telfer, (D ${ }^{b}$ \\ Corine Mathonière, ${ }^{c d}$ Rodolphe Clérac (D) ${ }^{\text {ef }}$ and Paul E. Kruger (D) *a
}

The dinuclear mesocate $\left[\mathrm{Fe}_{2} \mathrm{~L}_{3}\right]\left(\mathrm{BF}_{4}\right)_{4}, 1$, is a supramolecular building block for a microporous material. Structural analysis reveals that extensive noncovalent interactions in the solid state generate a 3D framework with microporous channels. These channels are permanently accessible to incoming guest molecules and adsorption isotherms demonstrate that the material has a high selectivity for $\mathrm{CO}_{2}$ over $\mathrm{N}_{2}$.

Over the past two decades, our understanding of microporous materials has progressed, steadily driven by their relevance to diverse applications such as gas separation and storage, catalysis, small-molecule separation and chemical sensing. ${ }^{1}$ 3D polymeric architectures, sustained by covalent and metal-ligand interactions, comprise the majority of microporous materials that have uniform and periodic structures. Notably, these include naturally occurring zeolites, ${ }^{2}$ metal-organic-frameworks (MOFs) ${ }^{3}$ and covalent-organicframeworks (COFs). ${ }^{4}$ More recently, however, an increasing number of studies have been devoted to porous materials comprised of discrete molecular entities. ${ }^{5}$ This class of compound, called molecular porous materials (MPMs), ${ }^{6}$ offer synthetic advantages over 3D polymeric materials owing to their enhanced solubility, which may aid their processability and incorporation into functional materials (e.g. attachment to surfaces, etc.). Two broad classes, depending on their structural conformation, describe the porosity within MPMs. Intrinsic porosity refers to compounds in which accessible void space is found inside a discrete entity e.g. organic cages, ${ }^{7}$

\footnotetext{
${ }^{a}$ MacDiarmid Institute for Advanced Materials and Nanotechnology, School of Physical and Chemical Sciences, University of Canterbury, Private Bag 4800, Christchurch 8041, New Zealand. E-mail: paul.kruger@canterbury.ac.nz

${ }^{b}$ MacDiarmid Institute for Advanced Materials and Nanotechnology, Institute of Fundamental Sciences, Massey University, Palmerston North 4442, New Zealand ${ }^{c}$ CNRS, ICMCB, UMR 5026, F-33600 Pessac, France

${ }^{d}$ Univ. Bordeaux, ICMCB, UMR 5026, F-33600 Pessac, France

${ }^{e}$ CNRS, CRPP, UMR 5031, F-33600 Pessac, France

${ }^{f}$ Univ. Bordeaux, CRPP, UMR 5031, F-33600 Pessac, France

$\dagger$ Electronic supplementary information (ESI) available: Synthetic details; SCXRD information; H-bond tables; crystal packing diagrams; TGA; PXRD; sorption data. CCDC 1841640. For ESI and crystallographic data in CIF or other electronic format see DOI: $10.1039 / \mathrm{c} 8 \mathrm{cc} 07227 \mathrm{~b}$
}

metal-organic-squares (MOSs) ${ }^{8}$ and polyhedra (MOPs) ${ }^{9}$ etc. Extrinsic porosity refers to structures in which void space exists between molecular units. Because the packing density in conventional molecule-based solids is high, the formation of MPMs possessing extrinsic porosity is rare. However, a reduction of the packing density via constructive and supportive supramolecular interactions between molecules can realise porous architectures. These supramolecular interactions typically involve hydrogen bonding, as in hydrogen-bonded organic frameworks (HOFs), ${ }^{10}$ supramolecular metal-organic frameworks (SMOFs), ${ }^{11}$ and supramolecular organic frameworks (SOFs), ${ }^{12}$ or noncovalent interactions involving strong dipoles. ${ }^{5 a, 12}$ There is much to learn from new examples of extrinsically porous materials, in particular the relationship between structural features and their properties, including stability, permanent porosity and solubility.

As part of our programme investigating $\mathrm{Fe}(\mathrm{II})$ dinuclear complexes $^{13}$ (Fig. 1), we report here a new and rare example of an extrinsically porous material comprising a supramolecular building block. The compound, $\left[\mathrm{Fe}_{2} \mathrm{~L}_{3}\right]\left(\mathrm{BF}_{4}\right)_{4}, \mathbf{1}$, where $\mathrm{L}=\mathrm{N}, \mathrm{N}-3$ bis[1-(2-pyrazinyl)ethylidene]isophthalo-hydrazide, was characterised using single crystal X-ray diffraction, and its permanent porosity was evaluated by gas adsorption isotherms using a range of adsorbates.

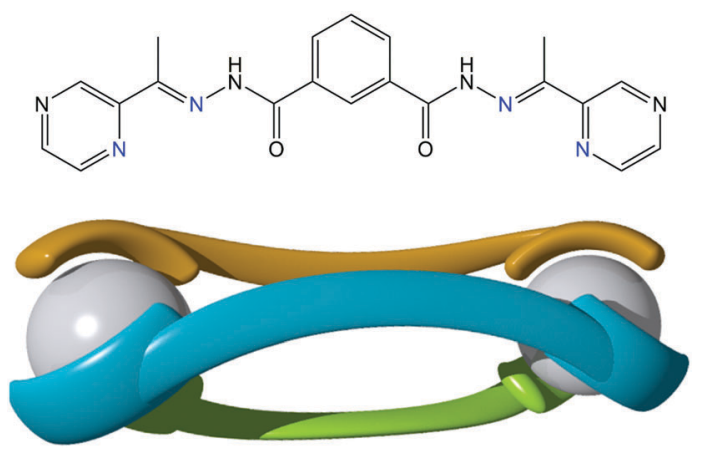

Fig. 1 (top) Structure of the ligand, L, used in the current study with coordinating $\mathrm{N}$-atoms coloured blue. (bottom) Schematic of a dinuclear triply stranded mesocate of composition $\left[\mathrm{M}_{2} \mathrm{~L}_{3}\right]^{n+}$. 

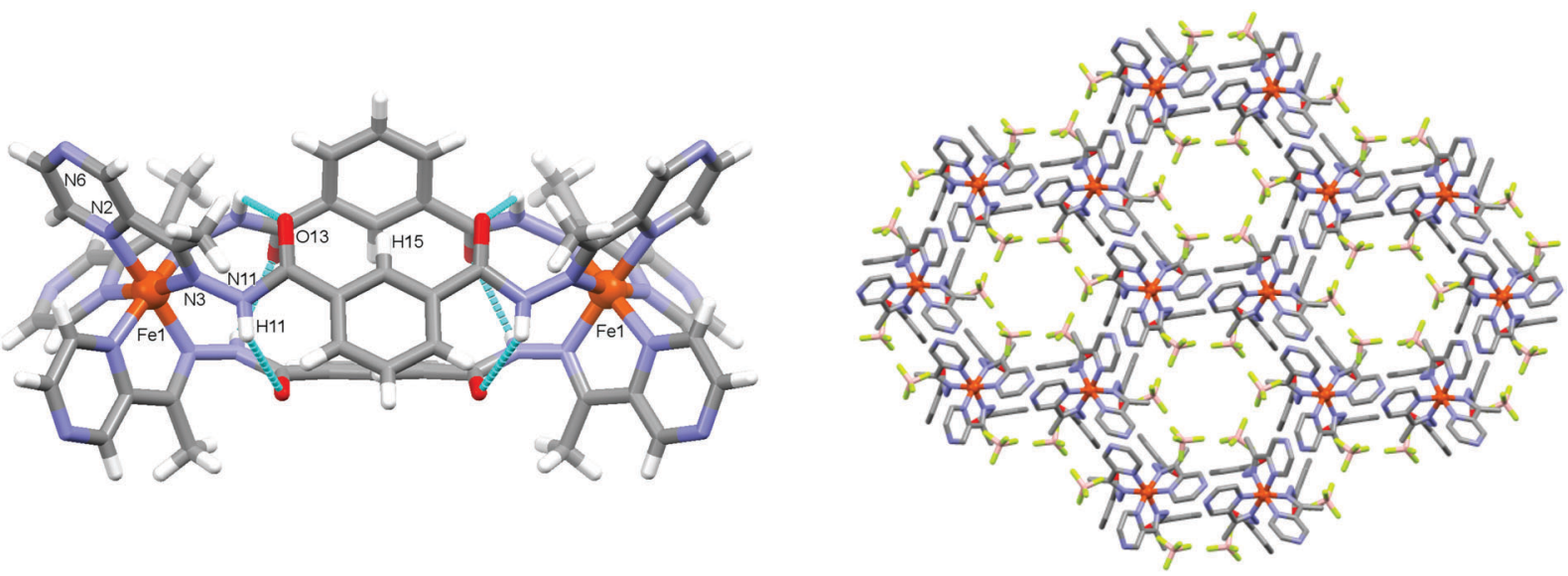

Fig. 2 (left) Molecular and crystal structure of the dinuclear mesocate complex, 1. Anions and disordered solvate molecules removed for clarity. (right) Packing diagram of $\mathbf{1}$ view down the crystallographic $\mathrm{c}$-axis. $\mathrm{H}$-atoms and disordered solvate molecules omitted for clarity.

A red coloured solution resulted when a suspension of $\mathbf{L}$ in nitromethane was stirred with $\mathrm{Fe}\left(\mathrm{BF}_{4}\right)_{2}(2: 3)$ at room temperature overnight. Single crystals of 1 were obtained by the diffusion of toluene anti-solvent into the nitromethane solution (see ESI†). The structure of 1 was determined from X-ray diffraction data collected at $120 \mathrm{~K}$. It crystallises in the hexagonal space group $\mathrm{P6}_{3} / \mathrm{m}$. The asymmetric unit contains one third of an $\mathrm{Fe}(\mathrm{II})$ atom coordinated to half of a ligand fragment featuring bidentate coordination via pyrazine (N2) and hydrazide (N3) nitrogen donors (Fig. 2 and Fig. S2, ESI $\dagger$ ). The average Fe-N bond length of 1.959(4) reveals the Fe(II) centre exists in the low spin state at $120 \mathrm{~K}^{14}$ The action of a 3-fold rotoinversion congruent with the crystallographic $c$-axis and a reflection about a mirror plane perpendicular to the crystallographic $c$-axis yields the dinuclear complex, $\left[\mathrm{Fe}_{2} \mathrm{~L}_{3}\right]^{4+}$ (Fig. 2). The three bis-bidentate ligand strands bridge $\mathrm{Fe}(\mathrm{II})$ centres to form a compact mesocate replete with attractive noncovalent inter-strand interactions. The hydrazide oxygen atoms (O13) are twisted with respect to the plane of the central phenyl rings to which they are attached and are in close contact with an adjacent hydrazide group

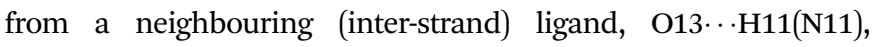
2.957(3) $\AA, 125.8^{\circ}$. Likewise, H15 from the central phenyl rings participate in an edge-to-face $\mathrm{C}-\mathrm{H} \cdots \pi$ interaction with an adjacent ligand strand, C15-H15 $\cdots \pi$ (centre-of-ring) $2.903 \AA$, $149.6^{\circ}$ (Fig. 2, Fig. S3; Tables S2, S3, ESI $\dagger$ ). These interactions likely support the mesocate conformation.

The mesocates pack in the crystal lattice via extensive supramolecular interactions, the most salient of which is the hydrogen-bonding between pyrazine and hydrazide groups of adjacent mesocates e.g.

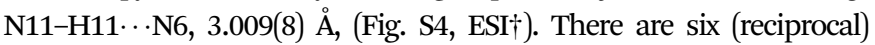
hydrogen bonds between adjacent pyrazine and hydrazide moieties of neighbouring supra-molecules, along with offset face-to-face $\pi-\pi$ interactions involving each pyrazine ring (centroid $\cdots$ centroid, 3.687(3) ̊). These interactions propagate down the crystallographic $c$-axis to generate a network containing $1 \mathrm{D}$ hexagonal channels parallel with the $c$-axis (Fig. 2, Fig. S4-S7; Tables S2, S3, ESI $\dagger$ ). The channel diameter at closest contact between van der Waals surfaces is $c a$. $5.8 \AA$. The tetrafluoroborate anions (which are disordered over two positions) line these $1 \mathrm{D}$ channels. Because of the high symmetry of the space
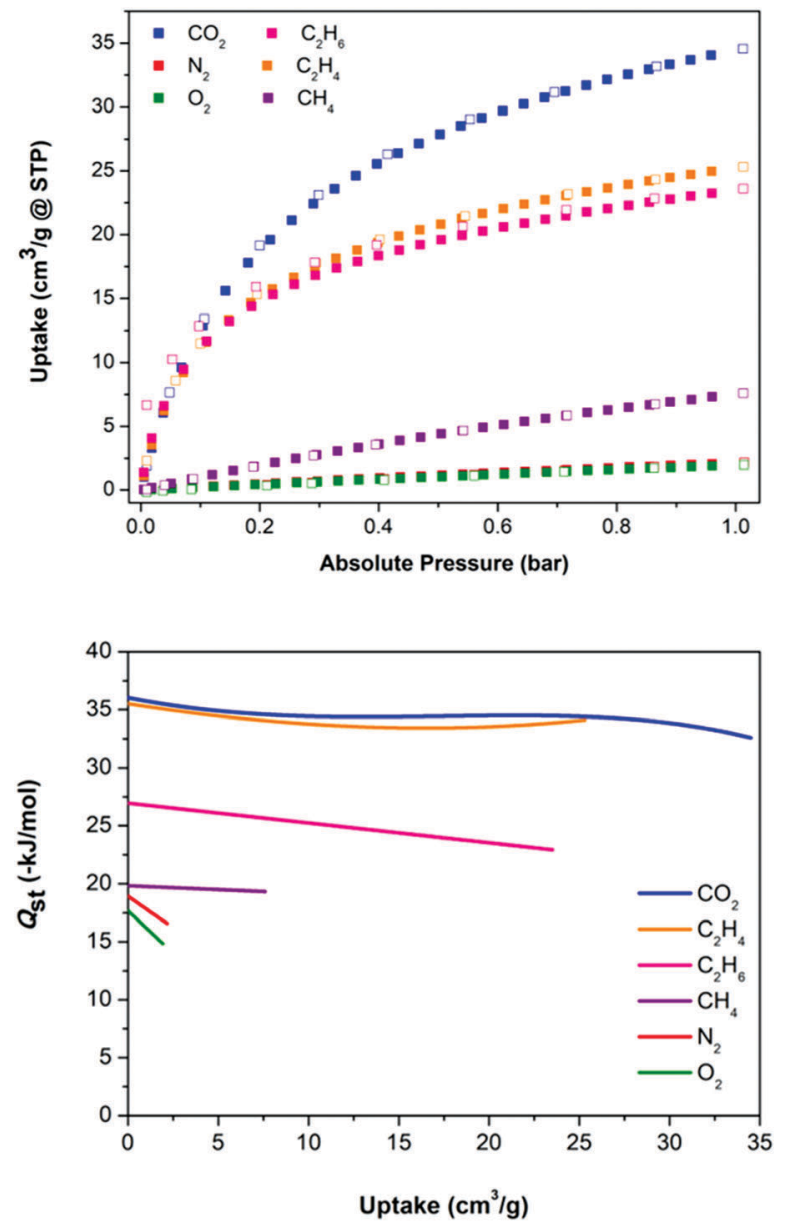

Fig. 3 (top) Adsorption isotherms for 1 at 295 K. (bottom) Plot of $Q_{\text {st }}$ as a function of loading for sorbates within 1.

group and disorder within the solvent molecules that reside within the channels, their identities could not be accurately determined and they were therefore treated by using the SQUEEZE programme embedded within PLATON..$^{15}$ The solvent accessible void was calculated to be $1164 \AA^{3}$ and accounts for $26 \%$ of the crystal volume. 
Table 1 Summary of gas sorption results for 1

\begin{tabular}{|c|c|c|c|c|c|c|}
\hline $\begin{array}{l}\text { Void } \\
\text { space }^{a}\end{array}$ & $\begin{array}{l}\mathrm{N}_{2} \text { uptake } \\
\left(\mathrm{cm}^{3} \mathrm{~g}^{-1}\right), \\
Q_{\mathrm{st}}^{c}\left(-\mathrm{kJ} \mathrm{mol}^{-1}\right)\end{array}$ & $\begin{array}{l}\mathrm{CO}_{2} \text { uptake }^{b} \\
\left(\mathrm{~cm}^{3} \mathrm{~g}^{-1}\right), \\
Q_{\text {st }}^{c}\left(-\mathrm{kJ} \mathrm{mol}^{-1}\right)\end{array}$ & $\begin{array}{l}\mathrm{CH}_{4} \text { uptake }^{b} \\
\left(\mathrm{~cm}^{3} \mathrm{~g}^{-1}\right), \\
Q_{\mathrm{st}}^{c}\left(-\mathrm{kJ} \mathrm{mol}^{-1}\right)\end{array}$ & $\begin{array}{l}\mathrm{C}_{2} \mathrm{H}_{4} \text { uptake }^{b} \\
\left(\mathrm{~cm}^{3} \mathrm{~g}^{-1}\right), \\
Q_{\mathrm{st}}^{c}\left(-\mathrm{kJ} \mathrm{mol}^{-1}\right)\end{array}$ & $\begin{array}{l}\mathrm{C}_{2} \mathrm{H}_{6} \text { uptake }^{b} \\
\left(\mathrm{~cm}^{3} \mathrm{~g}^{-1}\right), \\
Q_{\mathrm{st}}{ }^{c}\left(-\mathrm{kJ} \mathrm{mol}^{-1}\right)\end{array}$ & $\begin{array}{l}\mathrm{O}_{2} \text { uptake } \\
\left(\mathrm{cm}^{3} \mathrm{~g}^{-1}\right), \\
Q_{\mathrm{st}}^{c}\left(-\mathrm{kJ} \mathrm{mol}^{-1}\right)\end{array}$ \\
\hline $26 \%$ & $2.1,18.9$ & $34.5,36.0$ & $7.5,19.8$ & $25.3,35.5$ & $23.6,26.9$ & $1.9,17.7$ \\
\hline
\end{tabular}

${ }^{a}$ The accessible void space and micropore volume were calculated with the program PLATON ${ }^{15}$ using a probe radius of $1.2 \AA .{ }^{b}$ Uptakes reported

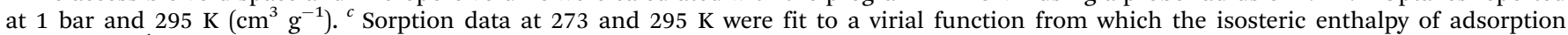
$\left(Q_{\mathrm{st}}, \mathrm{kJ} \mathrm{mol}^{-1}\right)$ was calculated.

Intrigued by the presence and size of the 1D channels within this material, and the structural resilience of the crystals when removed from their mother liquor, we set about to appraise its permanent porosity. Powder X-ray diffraction (PXRD) verified that activation of a batch of crystals via solvent exchange and drying in vacuo successfully retained the lattice structure (Fig. S8, ESI $\dagger$ ). The accessibility of the activated material to incoming guests molecules was confirmed by a $\mathrm{H}_{2}$ adsorption isotherm at $77 \mathrm{~K}$, which showed an uptake in excess of $60 \mathrm{~cm}^{3} \mathrm{~g}^{-1}$ (Fig. S9, ESI†). Hysteresis is also evident in this isotherm and is most probably a consequence of the small size of the pores and their one dimensional nature, which leads to slow diffusion of $\mathrm{H}_{2}$ at $77 \mathrm{~K}$. Consistent with the small size of the $1 \mathrm{D}$ channels, the uptake of $\mathrm{N}_{2}$ at $77 \mathrm{~K}$ was hampered by slow diffusion kinetics, which precluded the measurement of a conventional BET surface area. Gas uptake around room temperature was unhindered, however, and adsorption isotherms at 273 and $295 \mathrm{~K}$ were measured for the adsorbates $\mathrm{CO}_{2}, \mathrm{O}_{2}, \mathrm{~N}_{2}, \mathrm{CH}_{4}, \mathrm{C}_{2} \mathrm{H}_{4}$ and $\mathrm{C}_{2} \mathrm{H}_{6}$ (Fig. 3, Table 1 and Fig. S14, ESI $\dagger$ ). The small hysteresis in the $295 \mathrm{~K}$ isotherms for ethane possibly arises as a consequence of its larger size and indicates that we are approaching the size limit of the guests that can be adsorbed into the small 1D channels in $\mathbf{1}$.

From the range of adsorbates tested, the uptakes of $\mathrm{CO}_{2}$ and $\mathrm{N}_{2}$ are striking (Table 1). They reveal a significant uptake of $\mathrm{CO}_{2}$ and very little of $\mathrm{N}_{2}$ : at $295 \mathrm{~K}$ and 1 bar, uptake capacities of $\mathrm{CO}_{2}$ and $\mathrm{N}_{2}$ are equal to 34.5 and $2.1 \mathrm{~cm}^{3} \mathrm{~g}^{-1}$, respectively. This behaviour is a highly desirable feature touted for materials used in $\mathrm{CO}_{2}$ removal from flue gas streams and has been observed in other microporous physisorbent materials. ${ }^{16,17}$ The selectivity for $\mathrm{CO}_{2}$ over $\mathrm{N}_{2}$ in a 1:1 mixture was calculated using IAST to vary between 75 (low pressure) and 40 (1 bar), as shown in Fig. S25 (ESI $\dagger$ ). The selectivity of 1 for this gas pair is higher than those reported for a number of well-known MOFs, including CuBTC, ${ }^{18}$ SIFSIX-1-Cu ${ }^{6 b}$ and PCN-61. ${ }^{19}$ The selectivity for $\mathrm{CO}_{2}$ over methane is also impressive, varying between 16 and 20 (Fig. S25, ESI $\dagger$ ). Breakthrough curves for these gas pairs were simulated. These predict that $\mathbf{1}$ has the clear potential to separate $\mathrm{CO}_{2} / \mathrm{N}_{2}$ and $\mathrm{CO}_{2} / \mathrm{CH}_{4}$ mixtures on a bulk scale.

To evaluate the strength of interactions between adsorbates and 1, their isosteric heats of adsorption $\left(Q_{\mathrm{st}}\right)$ were calculated (Fig. 3 and Fig. S11-S23, ESI $\dagger$ ). For the six adsorbates, the magnitude of the $Q_{\mathrm{st}}$ values follow the same trend of the uptake capacities (Table 1). Notably, for $\mathrm{CO}_{2}$ the enthalpy at low loading is equal to $36 \mathrm{~kJ} \mathrm{~mol}^{-1}$, and for $\mathrm{N}_{2} 19 \mathrm{~kJ} \mathrm{~mol}^{-1}$. These values are on par with expectations based on the quadrupole moments and polarisabilities of these adsorbates, and are comparable with values observed for MOFs and related porous materials. ${ }^{20}$ Notably, the $Q_{\text {st }}$ for $\mathrm{N}_{2}$ is higher than that of $\mathrm{O}_{2}$.
This is the reverse of that expected on the basis of van der Waals interactions and is due to the quadrupole moment of $\mathrm{N}_{2}$ and its interaction with the strong electric field gradient of $\mathbf{1}$ that stems from the presence of the $\mathrm{BF}_{4}{ }^{-}$anions in the channels. A similar situation is seen in zeolites, which are also highly polar. For MOFs the situation is usually the reverse $\left(\mathrm{O}_{2}>\mathrm{N}_{2}\right)$ since their pores are typically less polar.

In conclusion, a new molecular porous material constructed from dinuclear mesocate complexes $\left[\mathrm{Fe}_{2}(\mathrm{~L})_{3}\right]\left(\mathrm{BF}_{4}\right)_{4}, \mathbf{1}$, has been detailed and represents a rare example of an extrinsically porous material. The formation of extensive supramolecular interactions between mesocate complexes serve to sustain an overall 3D architecture. 1D channels protruding through the structure have been studied by gas sorption experiments and reveal high $\mathrm{CO}_{2}$ over $\mathrm{N}_{2}$ selectivity, surpassing several wellknown MOFs. These results serve to emphasise the advantages offered by MPMs for selective gas sorption and provide design strategies for establishing new variants. Current work in our laboratory is looking at new variants of compound $\mathbf{1}$ by using related ligand sets in combination with other metal salts and results from these studies will be reported in due course.

The authors gratefully acknowledge the MacDiarmid Institute, the MBIE Catalyst Fund, and the Royal Society of New Zealand Marsden Fund; the Dumont d'Urville NZ-France Science \& Technology Support Programme for financial support and the New Zealand France Friendship Fund for the award of an Excellence Scholarship to BHW. The University of Bordeaux, the CNRS, the Région Nouvelle Aquitaine, the MOLSPIN COST action CA15128 and the GdR MCM-2: Magnétisme et Commutation Moléculaires is also thanked for their financial support. BHW gratefully acknowledges the receipt of the Roper Scholarship (UC). We thank Dr Dan Preston (UC) for assistance with Fig. 1.

\section{Conflicts of interest}

There are no conflicts to declare.

\section{Notes and references}

1 (a) F. Rouquerol, J. Roquerol, D. S. W. Sing, P. Llewellyn and G. Maurin, Adsorption by Powders and Porous Solids: Principles, Methodology and Applications, Elsevier, Poland, 2nd edn, 2014; (b) P. A. Wright, Microporous Framework Solids, Royal Society of Chemistry, Cambridge, 2008; (c) H. Yang, S. J. Bradley, X. Wu, A. Chan, G. I. N. Waterhouse, T. Nann, J. Zhang, P. E. Kruger, S. Ma and S. G. Telfer, ACS Nano, 2018, 12, 4594; (d) H. Yang, S. J. Bradley, A. Chan, G. I. N. Waterhouse, T. Nann, P. E. Kruger and S. G. Telfer, J. Am. Chem. Soc., 2016, 138, 11872. 
2 R. Xu, W. Pang, J. Yu, Q. Huo and J. Chen, Chemistry of Zeolites and Related Porous Materials: Synthesis and Structure, John Wiley \& Sons Ltd, Singapore, 2007.

3 (a) Metal-Organic Framework Materials, ed. C. M. Lukehart and L. R. MacGillivray, John Wiley \& Sons Ltd, United Kingdom, 2014; (b) The Chemistry of Metal-Organic Frameworks: Synthesis, Characterization, and Applications, ed S. Kaskel, Wiley-VCH Verlag GmbH \& Co., 2016; (c) D. C. Young, H. Yang, S. G. Telfer and P. E. Kruger, Inorg. Chem., 2017, 56, 12224; (d) H. S. Scott, S. Mukherjee, D. R. Turner, M. I. J. Polson, M. J. Zaworotko and P. E. Kruger, CrystEngComm., 2018, 20, 1193; (e) S. J. Lee, C. Doussot and S. G. Telfer, Cryst. Growth Des., 2017, 17, 3185; ( $f$ ) K. M. Patil, S. G. Telfer, S. C. Moratti, O. T. Qazvini and L. R. Hanton, CrystEngComm, 2017, 19, 7236.

4 S.-Y. Ding and W. Wang, Chem. Soc. Rev., 2013, 42, 538.

5 (a) N. B. McKeown, J. Mater. Chem., 2010, 20, 10588; (b) J. Tian, P. K. Thallapally and B. P. McGrail, CrystEngComm, 2012, 14, 1909; (c) A. G. Slater and A. I. Cooper, Science, 2015, 348, 6238; (d) C. G. Bezzu, M. Helliwell, J. E. Warren, D. R. Allan and N. B. McKeown, Science, 2010, 327, 1627.

6 (a) H. Kim, Y. Kim, M. Yoon, S. Lim, S. M. Park, G. Seo and K. Kim, J. Am. Chem. Soc., 2010, 132, 12200; (b) P. S. Nugent, V. L. Rhodus, T. Pham, K. Forrest, L. Wojtas, B. Space and M. J. Zaworotko, J. Am. Chem. Soc., 2013, 135, 10950.

7 T. Tozawa, J. T. A. Jones, S. I. Swamy, S. Jiang, D. J. Adams, S. Shakespeare, R. Clowes, D. Bradshaw, T. Hasell, S. Y. Chong, C. Tang, S. Thompson, J. Parker, A. Trewin, J. Bacsa, A. M. Z. Slawin, A. Steiner and A. I. Cooper, Nat. Mater., 2009, 8, 973.

8 S. Wang, T. Zhao, G. Li, L. Wojtas, Q. Huo, M. Eddaoudi and Y. Liu, J. Am. Chem. Soc., 2010, 132, 18038.

9 (a) A. C. Sudik, A. R. Millward, N. W. Ockwig, A. P. Côté, J. Kim and O. M. Yaghi, J. Am. Chem. Soc., 2005, 127, 7110; (b) M. B. Duriska, S. M. Neville, J. Lu, S. S. Iremonger, J. F. Boas, C. J. Kepert and S. R. Batten, Angew. Chem., Int. Ed., 2009, 121, 9081; (c) G. A. Craig, P. Larpent, S. Kusaka, R. Matsuda, S. Kitagawa and S. Furukawa, Chem. Sci., 2018, 9, 6463; (d) J.-R. Li and H.-C. Zhou, Nat. Chem., 2010, 2, 893; (e) W. Lu, D. Yuan, A. Yakovenko and H.-C. Zhou, Chem. Commun., 2011, 47, 4968; $(f)$ J. M. Teo, C. J. Coghlan, J. D. Evans, E. Tsivion, M. Head-Gordon, C. J. Sumby and C. J. Doonan, Chem. Commun., 2016, 52, 276; $(g)$ K. Xiong, F. Jiang, Y. Gai, D. Yuan, L. Chen, M. Wu, K. Su and M. Hong, Chem. Sci., 2012,
3, 2321; (h) D. Preston, K. F. White, J. E. M. Lewis, R. A. S. Vasdev, B. F. Abrahams and J. D. Crowley, Chem. - Eur. J., 2017, 23, 10559.

10 H. Wang, B. Li, H. Wu, T.-L. Hu, Z. Yao, W. Zhou, S. Xiang and B. Chen, J. Am. Chem. Soc., 2015, 137, 9963.

11 J. Thomas-Gipson, G. Beobide, O. Castillo, M. Fröba, F. Hoffmann, A. Luque, S. Pérez-Yáñez and P. Román, Cryst. Growth Des., 2014, $14,4019$.

12 J. Tian, H. Wang, D.-W. Zhang, Y. Liu and Z.-T. Li, Natl. Sci. Rev., $2017,4,426$.

13 (a) R. J. Archer, C. S. Hawes, G. N. L. Jameson, V. McKee, B. Moubaraki, N. F. Chilton, K. S. Murray, W. Schmitt and P. E. Kruger, Dalton Trans., 2011, 40, 12368; (b) D. Pelleteret, R. Clérac, C. Mathonière, E. Harté, W. Schmitt and P. E. Kruger, Chem. Commun., 2009, 221; (c) R. J. Archer, H. S. Scott, M. I. J. Polson, B. E. Williamson, C. Mathonière, M. Rouzières, R. Clérac and P. E. Kruger, Dalton Trans., 2018, 47, 7965.

14 Single crystal X-ray diffraction data were also collected at $298 \mathrm{~K}$. While the quality of the crystal was poor, the data gave a reasonable structural solution in the same $P 6_{3} / m$ space group. The average $\mathrm{Fe}-\mathrm{N}$ bond length of $1.958(10) \AA$ reveals that the Fe(II) centre remains in the low spin state at $298 \mathrm{~K}$.

15 A. L. Spek, PLATON SQUEEZE: a tool for the calculation of the disordered solvent contribution to the calculated structure factors, Acta Crystallogr., Sect. C: Cryst. Struct. Commun., 2015, 71, 9.

16 D. Aaron and C. Tsouris, Sep. Sci. Technol., 2005, 40, 321.

17 (a) J. Thomas-Gipson, G. Beobide, O. Castillo, J. Cepeda, A. Luque, S. Pérez-Yáñez, A. T. Aguayo and P. Román, CrystEngComm, 2011, 13, 3301; (b) K. M. Ok, J. Sung, G. Hu, R. M. J. Jacobs and D. O'Hare, J. Am. Chem. Soc., 2008, 130, 3762; (c) T. K. Maji, R. Matsuda and S. Kitagawa, Nat. Mater., 2007, 6, 142.

18 Z. Zhang, Y. Zhao, Q. Gong, Z. Lib and J. Li, Chem. Commun., 2013, 49, 653.

19 B. Zheng, J. Bai, J. Duan, L. Wojtas and M. J. Zaworotko, J. Am. Chem. Soc., 2011, 133, 748.

20 (a) H. S. Scott, N. Ogiwara, K.-J. Chen, D. G. Madden, T. Pham, K. Forrest, B. Space, S. Horike, J. J. Perry, S. Kitagawa and M. J. Zaworotko, Chem. Sci., 2016, 7, 5470; (b) K.-J. Chen, H. S. Scott, D. G. Madden, T. Pham, A. Kumar, A. Bajpai, M. Lusi, K. A. Forrest, B. Space, J. J. Perry and M. J. Zaworotko, Chem, 2016, 1, 753; (c) P. Nugent, Y. Belmabkhout, S. D. Burd, A. J. Cairns, R. Luebke, K. Forrest, T. Pham, S. Ma, B. Space, L. Wojtas, M. Eddaoudi and M. J. Zaworotko, Nature, 2013, 495, 80. 